\title{
The Flipped Classroom: A Twist On Teaching
}

Stacy M.P. Schmidt, California State University, Bakersfield, USA

David L. Ralph, Pepperdine University, USA

\begin{abstract}
The traditional classroom has utilized the "I Do", "We Do", "You Do" as a strategy for teaching for years. The flipped classroom truly flips that strategy. The teacher uses "You Do", "We Do", "I Do" instead. Homework, inquiry, and investigation happen in the classroom. At home students participate in preparation work including watching videos, PowerPoint's, and completing readings. After completing the preparation work, students arrive in class ready to start solving problems, analyzing text, or investigating solutions. The flipped classroom is fairly new in the teaching field as a strategy for teaching. It has been used by teachers from elementary school to graduate school. As with most strategies, the flipped classroom has a variety of ways to implement in the classroom. This article is a case study of the flipped classroom. It reviews and provides research on the implementation of the flipped classroom. In addition, the article provides a variety of implementation methods and tools to be utilized in a flipped classroom. As with all teaching strategies there are advantages and disadvantages to the flipped classroom which are explained as well.
\end{abstract}

Keywords: Flipped Classroom; Teaching Strategies; Education

\section{INTRODUCTION}

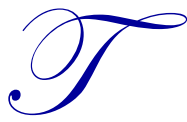

he traditional classroom has utilized the "I Do", "We Do", "You Do" as a strategy for teaching for years. The flipped classroom truly flips that strategy. The teacher uses "You Do", "We Do", "I Do" instead. Homework, inquiry, and investigation happen in the classroom. At home students participate in preparation work including watching videos, PowerPoints, and completing readings. After completing the preparation work, students arrive in class ready to start solving problems, analyzing text, or investigating solutions.

The flipped classroom is fairly new in the teaching field as a strategy for teaching. It has been used by teachers from elementary school to graduate school. As with most strategies, the flipped classroom has a variety of ways to implement in the classroom.

\section{Why The Flipped Classroom}

The term flipping comes from the idea of swapping homework for classwork (Ash, 2012). When students go home to work on homework, some of them have well educated parents that can assist them with the work while others have parents that are not knowledgeable in the content and cannot assist them with their homework. Thus according to Ash (2012), students are able to return to class with the content and then receive assistance with the homework from the expert in the field -the teacher during class time. The flipped classroom provides the students with in class support for completing work. The flipped classroom provides more time for hands on activities and content inquiry and analysis. Fulton (2012) also found that the flipped classroom causes "students to take more responsibility for their own learning". Students also have access to the content at home so if they are absent due to illness they can easily catch up and do not miss out on vital lectures. 


\section{Flipping Your Classroom: The Research}

Flipping your classroom does not mean you can never lecture or that your classroom is always flipped. The teacher is still necessary in the flipped classroom. The teacher still has to plan and prepare for every class. The flipped classroom also does not require technology to use.

Ash (2012) suggested the following 5 tips for flipping your classroom:

1. Don't get hung up on creating your own videos.

2. Be thoughtful about what parts of your class you decide to "Flip" and when.

3. If possible, find a partner to create videos with.

4. Address the issue of access early.

5. Find a way to engage students in the videos.

A common practice of teachers utilizing a flipped classroom is videos of the lectures. The videos are used in various ways. Teachers found that the use of short 10-15 minute videos is the best way to incorporate the videos. Resources have surfaced on the web of content information in a wide range of subject matter. Some websites provide premade videos, tutorials, and interfaces on the subject matter. The most successful flipped classrooms report that they utilize videos of the content that they have gotten from a variety of places. By obtaining videos from other sources the students indicate they are more engaged and found the information refreshing. Videos from the same person can become mundane and boring. Taking boring lectures and recording them and making students watch them on their own time is not the purpose of the flipped classroom. Voice-over PowerPoints are also mundane and boring. Students will disengage and are likely not going to watch them with their full attention. One means of making the videos is the use of simple "one take" videos (Brunsell \& Horejsi, 2013). "To create these videos, all you need is an inexpensive digital camera, tripod, white panel board, and dry erase markers. Teachers outline their presentation with visual aids on a series of small whiteboards. Then, they simply record themselves talking through the series of whiteboards. The benefit of this approach is that videos can be created quickly; and by having the teacher on camera, students connect with both the content and their teacher."

Budget constraints do not have to prevent a teacher from utilizing the flipped classroom. The first consideration that must be made when incorporating a flipped classroom is what technology is available to not only the teacher but the students as well. If a teacher requires students to use the internet or view videos for homework, the students need to have access to this technology. Some teachers are shocked to discover how many of their students still do not even have a computer at home let alone access to the internet. Some teacher's work addresses this by creating a means to provide access to these students while other teachers change their medium away from the computer. Whether it is watch videos or complete a reading, the teacher cannot just require the task to be completed. The student needs to be engaged in the process to assure its completion and the students acquiring the knowledge presented. This can be done in many ways. Teachers are even getting creative with this aspect of the flipped classroom. It can be as simple as having the students complete a worksheet or answer questions as they read or watch the video. Having the students write questions about what further information they need is helpful in moving to the in class portion of the lesson. Having the students identify and define words they were not familiar with is also helpful.

In some instances the flipped classroom provides a solution to budget issues. "A Minnesota high school with severe budget constraints enlisted YouTube in its successful effort to boost math competency scores (Fulton, 2012)". The school did not have money for new textbooks and were utilizing outdated material. The teachers used YouTube to store videos to accompany materials they created and implemented themselves. Working together the math teachers were able to create videos and then create activities, worksheets, and projects that were utilized in the class. "Unable to afford an expensive course management system, they turned to Moodle, a free online learning management system". (Fulton, 2012) Moodle is free to use and provides you with the opportunity to use a variety of online tools. This can be used to store documents, videos, and information for students if your school cannot afford an online portal of their own.

The flipped classroom should not just be a band wagon that all teachers jump on to use in their classrooms. It is vital that teachers approach the flipped classroom with care and knowledge. 
Neilsen (2012) identified the following five reasons to implement the flipped classroom with caution:

1. Many of our students don't have access to technology at home

2. Flipped homework is still homework and there are a growing number of parents and educators who believe mandatory homework needlessly robs children of their after-school time.

3. Flipping instruction might end up just providing more time to do the same type of memorization and regurgitation that just doesn't work.

4. If we really want transformation in education, one thing we must do is stop grouping students by date of manufacture, which the flipped classroom is ideally suited for. True flipping should include a careful redesign of the learning environment, but this is often overlooked.

5. The flipped classroom is built on a traditional model of teaching and learning: I lecture, you intake

On the other hand, Millard (2012) found 5 reasons the flipped classroom works:

1. Increases student engagement

2. Strengthens team-based skills

3. Offers personalized student guidance

4. Focuses Classroom Discussion

5. Provides Faculty Freedom

The flipped network (2012) conducted a study of teachers incorporating the flipped classroom at the junior high and secondary school. The study indicated that $99 \%$ of the teachers that incorporated the flipped classroom will continue to use it. $67 \%$ reported improvements in student performance and $80 \%$ reported improvements in student engagement. $71 \%$ of the teachers put $50 \%$ or more of their instruction online. Science was the most flipped subject at $46 \%$, math was $32 \%$ and ELA was only $12 \%$. $95 \%$ of the study consisted of secondary teachers.

\section{Flipping Your Classroom: The Study}

Classroom teachers were surveyed regarding the flipped classroom. 58 teachers responded to the survey. Of the 58 teachers 21 were brand new teachers with 1-2 years experience. 13 teachers had 2-5 years of experience and 24 teachers had more than 5 years of teaching experience.

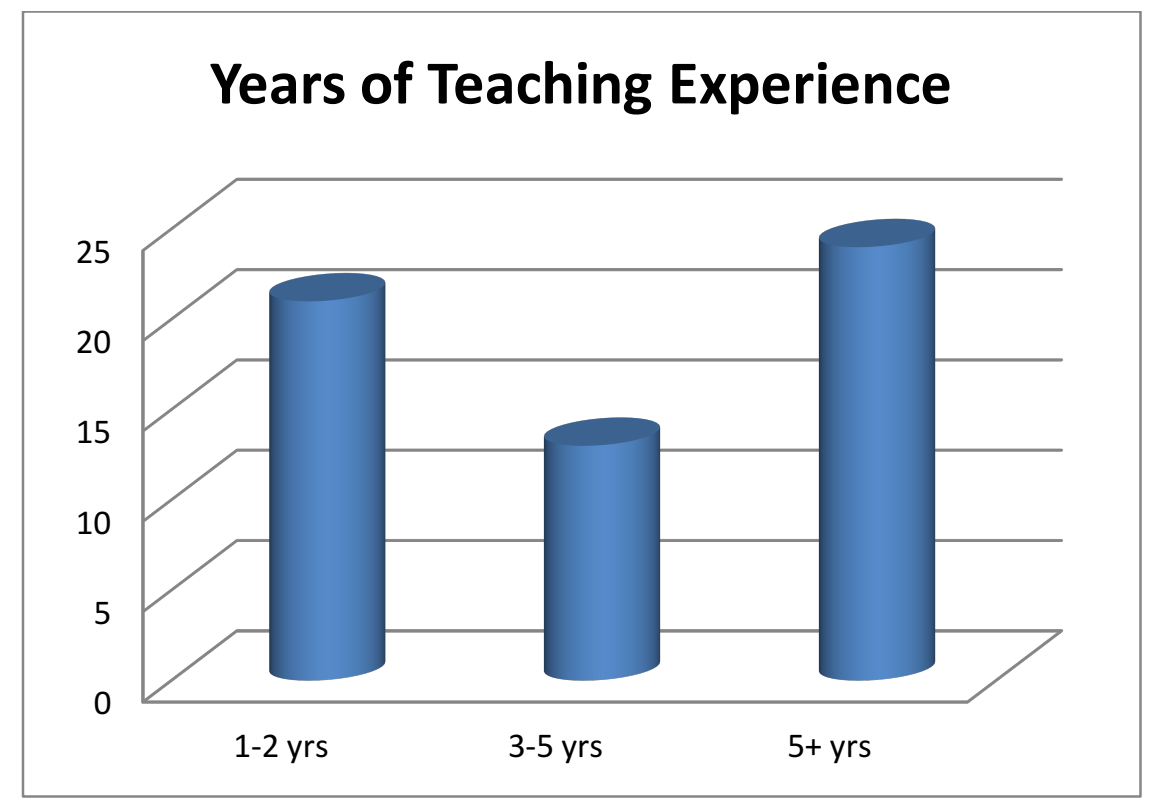


Of the 58 teachers only 3 teachers utilized a flipped classroom.

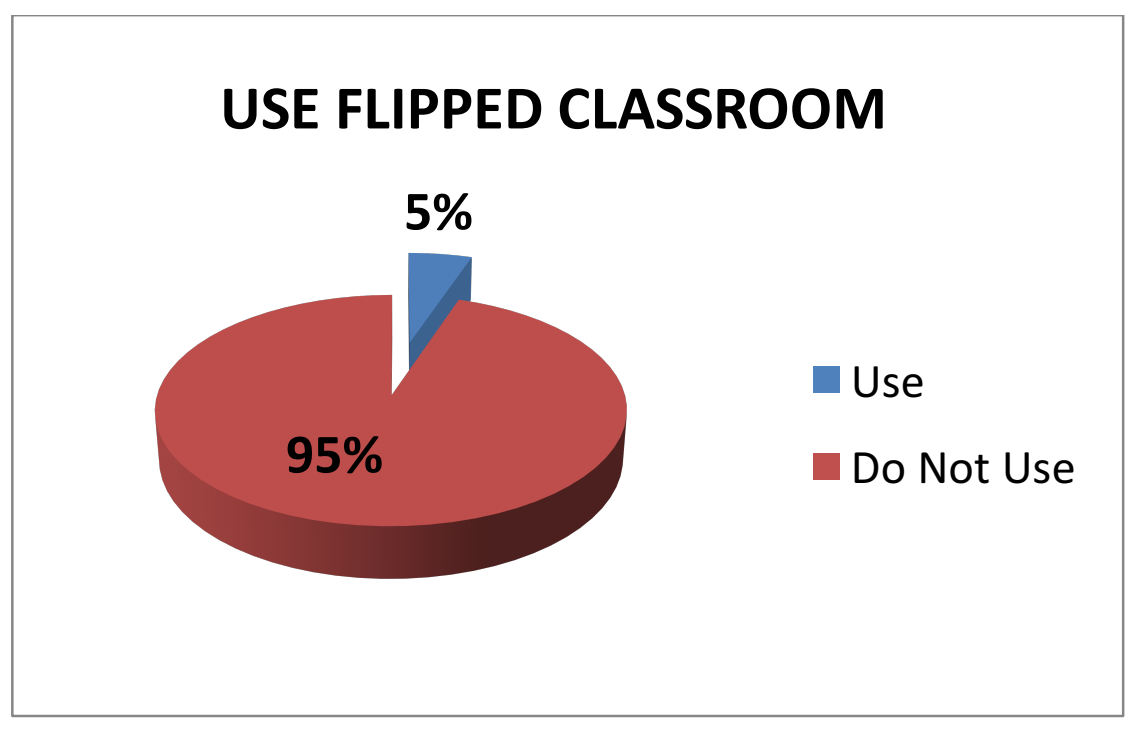

One class was high school math, one class was a high school Social Science, and one class was an elementary classroom. Of the 58 teachers, 15 were knowledgeable of the flipped classroom, 13 were somewhat knowledgeable, and 30 were not very knowledgeable.

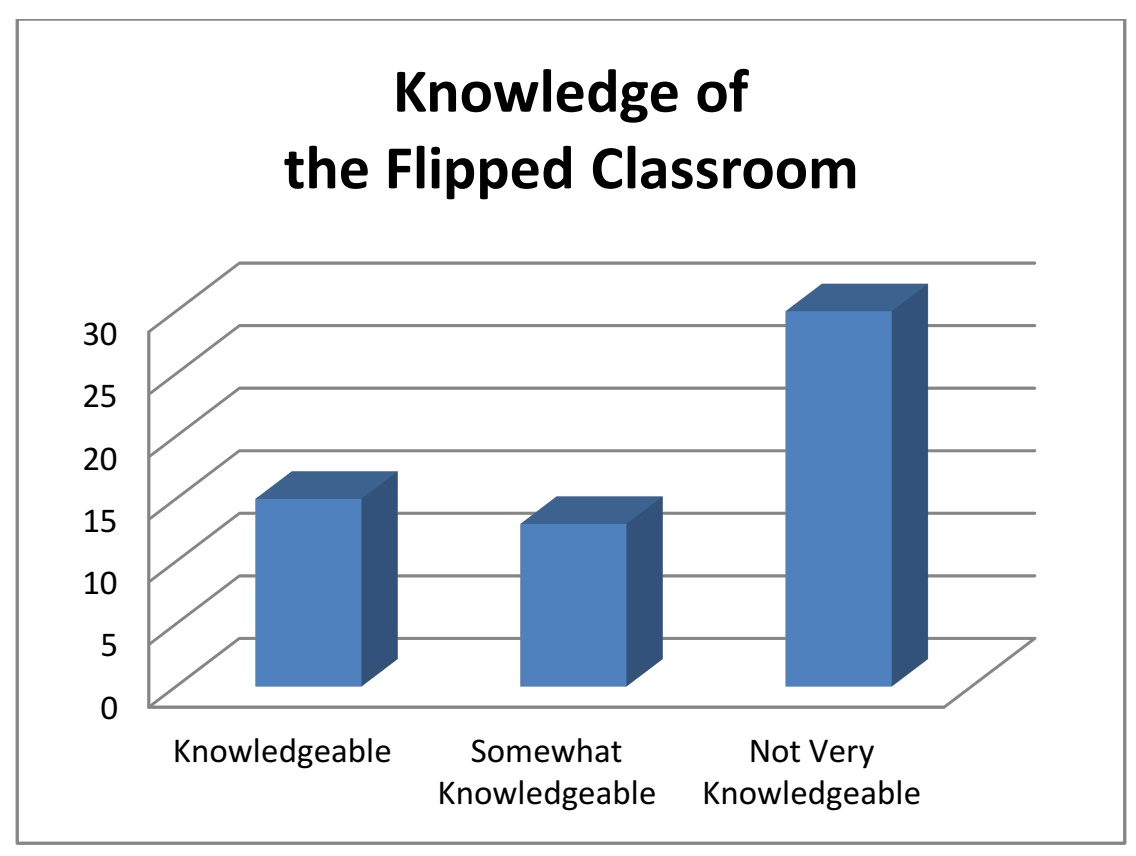

The three flipped classrooms utilized different strategies and techniques. All of the teachers reported increased student engagement, improved student scores, and less incomplete assignments. The next paragraphs describe the different flipped classrooms utilized.

For the at home work, the high school math teacher incorporated fully online resources. The teacher utilized an online resource, the Khan Academy. Students were assigned videos to watch, interactive challenges, and quizzes. The Khan Academy website is located at khanacademy.org. The teacher is referred to as a Coach on the site. The 
teacher selects which information to assign to the students. The students watch the videos, practice problems, and take quizzes. The teacher has access to the results instantly on the website. This provides the teacher with information on what the students have mastered and what information needs further instruction. Teachers then use this information for instruction in class the following day. The students arrived at class with questions from the lesson and the teacher immediately dove into working out problems with the students and answering their questions. The teacher reported that the students were more engaged in class as a result of using the flipped classroom.

The teacher also stated that the students reported that this method provided them with an opportunity to get better support working out the problems. The students often do not realize they do not understand a concept until they start actually analyzing and solving problems. Some students have parents at home that can assist them when they struggle with the math but a majority of the students do not have anyone at home that has enough knowledge in the content area of mathematics to help them. So with the flipped classroom they arrive and class and start to solve questions and the expert (the teacher) monitors their progress and is available for guidance. Thus, the result is improved scores for the mathematics students. In addition, the students are less likely to get frustrated and give up working on the math when the teacher is there to further explain the information and processes.

The High School Social Science teacher used both online and offline resources in her flipped classroom. She often has the students read the textbook for homework. Whenever textbook readings are assigned, the teacher always requires the students complete a task while reading the text. These activities can be a graphic organizer, sentence frames, or open ended questions. The teacher often has the students write down what questions they still have or clarifications they need. She then has them submit them to her in one of three ways:

1. Hand in when they arrive at class the next day

2. Email them to her the night before

3. Write them in a blog or online discussion board the night before

The teacher then uses these questions to guide her lesson and assure the students have a full grasp of the material.

The teacher often incorporates online readings, videos, and websites as well for homework. The students complete these assignments at home. While completing these assignments, the students often complete activities while doing the homework. Sometimes this works is taking notes of the reading or creating an outline of the material. Then in class, the teacher skips the lecture and begins with analysis, application, and comparisons. The result is that discussions are more engaging and deeper the teacher reports.

The elementary teacher is faced with many students that do not have access to technology at home. Some students have no computers and some that have computers have no internet access. Therefore, the elementary teacher uses an exclusively offline flipped classroom. The teacher assigns the students to complete readings including the textbooks. While completing the readings, students are sometimes required to highlight key points in one color, new vocabulary in another color, and confusing or points that need clarification in another color. Other times students are required to write notecards of specific information. It might be main characters, key dates, points for clarification, or vocabulary cards for example. This frontloads the material and exposes the children to the information prior to coming to class. Some students still do not complete the homework reports the teacher. The teacher makes it clear that the flipped classroom is not a solution to incomplete homework. On the other hand, she did report that students are more encouraged to be prepared for class as the expectation is for students to know the material and be able to actively participate in the class activities and discussions

\section{CONCLUSION}

The flipped classroom is a lot of work to utilize and the lack of access to technology by students make it unattractive for teachers to use. As access is more readily available and more data is available to support the improved learning and student engagement, more teachers will be willing to implement a flipped classroom. The flipped classroom can be used to enhance learning and is not meant as a means to just record boring class lectures and force the students to watch them on their own time. 
If utilizing videos it is important to be aware of student access to the videos. Some schools band YouTube therefore, if you plan on using YouTube to house your videos students would not be able to access these on school grounds unless you got the band lifted. In addition, short videos are key to a successful conversion of course material if utilized appropriately. Use short precise videos to cover the material. Segment the material if possible to deliver it in chunks to the students. Students also indicate that watching videos of the same person whether their teacher or someone else gets boring.

Do not feel obligated to create all of the material as your original work product. The internet has a large variety and quantity of resources and materials for teachers to incorporate into their classroom. Not only does this reduce the workload for the teacher but provides variety for the students. Sometimes creating your own online resources often requires more technological skills then you possess. Time is a valuable resource that is precious to teachers. These online resources take the place of hours of preparation that would be required to create this material. There are a wide range of resources that are available including but not limited to: online readings, videos on YouTube, and interactive websites. The Khan Academy at khanacademy.com is a resource that not online has online video lessons but contains interactive activities and quizzes and is completely free for students as well as teachers. Sophia.org is another free website that has a variety of lessons and videos in a range of subject areas and grade levels.

The more interactive the work at home is the more successful the flipped classroom. Students will be more apt to complete the at home work when they are engaged and interested. Variety in content, activities, and videos will engage students. As the flipped classroom becomes more and more utilized more research and resources will need to be completed.

\section{AUTHOR BIGRAPHIES}

Stacy M. P. Schmidt is a Professor at California State University, Bakersfield in the Department of Teacher Education. She serves as the Director of Teacher Credentialing at the Antelope Valley.

David L. Ralph is a Professor at Pepperdine University in the Department of Economics, Law and Marketing. He serves as the Chair of the Department of Economics, Law and Marketing.

\section{REFERENCES}

Ash, K. (2012) Educators View 'Flipped' Model' With a More Critical Eye. Education Week, pS6-S7.

Brunsell, E. and Horejsi, M. (2013) Flipping Your Classroom in One 'Take'. The Science Teacher, p.8.

Flipped Learning Network (2012) What do teachers who've flipped their classrooms have to report? Technology and Learning, p. 12.

Fulton, K. (2012) The Flipped Classroom: Transforming Education at Byron High School, T.H.E. Journal, p18-20.

Millard, E. (2012) 5 Reasons Flipped Classrooms Work. University Business, p.26-29.

Nielsen, L. (2012) Five Reasons I'm Not Flipping Over The Flipped Classroom. Technology and Learning, p. 46. 